\title{
Presence of Reactive Microglia and Neuroinflammatory Mediators in a Case of Frontotemporal Dementia with P301S Mutation
}

\author{
Arianna Bellucci ${ }^{\mathrm{a}-\mathrm{c}}$ Orso Bugiani ${ }^{\mathrm{d}}$ Bernardino Ghetti ${ }^{\mathrm{e}} \quad$ Maria Grazia Spillantini ${ }^{\mathrm{a}}$ \\ a Department of Clinical Neurosciences, Brain Repair Centre, University of Cambridge, Cambridge, UK; ${ }^{b}$ Division of \\ Pharmacology, Department of Biomedical Sciences and Biotechnologies, University of Brescia, Brescia, \\ ${ }^{C}$ Department of Preclinical and Clinical Pharmacology, University of Florence, Florence, and ${ }^{\mathrm{d}}$ Carlo Besta Neurological \\ National Institute, Milan, Italy; ${ }^{e}$ Department of Pathology and Laboratory of Medicine, Indiana University, \\ Indianapolis, Ind., USA
}

\section{Key Words}

Frontotemporal dementia and parkinsonism linked to chromosome 17 with tau mutations - Neuroinflammation • Microglia $\cdot$ Interleukin $1 \beta \cdot$ Cyclooxygenase 2

\begin{abstract}
Background: Recent findings, showing the presence of an inflammatory process in the brain of transgenic mice expressing P301S mutated human tau protein, indicate that neuroinflammation may contribute to tau-related degeneration in frontotemporal dementia and parkinsonism linked to chromosome 17 with tau mutations (FTDP-17T). Objective: To investigate the occurrence of neuroinflammatory changes in the brain of a patient affected by FTDP-17T associated with the P3015 mutation and showing a frontotemporal dementia phenotype as well as in the brain of a patient affected by another FTDP-17T phenotype: multiple system tauopathy with presenile dementia. Methods: We used immunohistochemical methods to visualize activated microglia, interleukin-1 $\beta$ (IL-1 $\beta$ )-, cyclooxygenase-2 (COX-2)-expressing cells. Results: In the brain of the patient with the P301S mutation, a strong neuroinflammatory reaction was present. Activated microglia/infiltrating macrophages expressing the cluster of differentiation 68 and major histocampatibility complex class II cell surface receptors, encod-
\end{abstract}

ed by the human leukocyte antigen DP-DQ-DR, were detected in the cortex and hippocampus. IL-1 $\beta$ and COX-2 expression were induced in neuronal and glial cells. These neuroinflammatory changes were different from those observed in the brain of the patient bearing the +3 mutation, where macrophage infiltration was absent, microglial cells displayed an earlier stage of activation and COX-2 was not detected. Conclusions: Our findings suggest that microglial activation and the production of proinflammatory mediators by phospho-tau-positive neurons and glial cells may differentially contribute to neuronal death and disease progression in neurodegenerative tauopathies.

Copyright $\odot 2011$ S. Karger AG, Basel

\section{Introduction}

Intracellular filamentous inclusions made of microtubule-associated tau protein are characteristic histopathological features of a series of neurodegenerative diseases named tauopathies, such as frontotemporal dementia and parkinsonism linked to chromosome 17 with tau mutations (FTDP-17T), progressive supranuclear palsy, corticobasal degeneration (CBD) and Alzheimer's disease (AD). FTDP-17T is a hereditary neurodegenerative disorder which is characterized by a spectrum of clinical phe-

\section{KARGER}

() 2011 S. Karger AG, Basel

Fax +4161306 1234

E-Mail karger@karger.ch

www.karger.com
Accessible online at:

www.karger.com/ndd
Dr. Arianna Bellucci, $\mathrm{PhD}$

Division of Pharmacology, Department of Biomedical Sciences and Biotechnologies University of Brescia, Viale Europa No. 11

IT-25123 Brescia (Italy)

Tel. +39030 371 7512, Fax +39030 371 7529, E-Mail bellucci@med.unibs.it 
notypes ranging from an FTD-predominant to a parkinsonism-predominant type $[1,2]$.

Numerous mutations on the tau gene have been linked to FTDP-17T [3]. In 1999, Bugiani et al. [4] described the first family with the P301S tau gene mutation, which was associated with FTD and CBD phenotypes in different members of the same family [5]. Indeed, the father was affected by FTD with an early-onset dementia, rigidity and epilepsy. The son, at a similar age of onset, showed CBD symptoms, indicating that the same gene mutation could lead to different clinical phenotypes. Neuropathologically, the father presented an extensive filamentous pathology made of hyperphosphorylated tau in neurons, oligodendroglia and astrocytes. Cellular degeneration and cerebral atrophy prevailed in frontotemporal regions, basal ganglia and upper brainstem. Only clinical and genetic data are available for the son with CBD.

In 2002, a transgenic mouse model expressing human P301S-mutated tau protein under the control of the Thy1 promoter was produced and characterized [6]. Homozygous animals from this line develop a neurological phenotype dominated by a severe motor deficit and motor neuron degeneration at 5-6 months of age. In these mice, numerous filamentous tau deposits are found in neurons in both brain and spinal cord. Tau aggregates are associated with marked neuroinflammation [7]. Indeed, besides microgliosis, many neurons in the brainstem and spinal cord are strongly immunoreactive for interleukin $1 \beta$ (IL-1 $\beta$ ) and cyclooxygenase 2 (COX-2). These tau-associated inflammatory events may play a significant role in the progression of tau-related diseases. On this line, another study on a different P301S transgenic mouse model [8] showed that microglia activation, hippocampal synapse loss and impaired synaptic function precede fibrillary tangle formation. Immunosuppression of young P301S transgenic mice attenuated tau pathology and increased their lifespan. Consistently, the anti-inflammatory action of donepezil has recently been found to ameliorate tau pathology, synaptic loss and neurodegeneration in this P301S transgenic mouse line [9], thereby linking neuroinflammation to the progression of the disease.

Brain inflammatory reaction, firstly induced as a defense response against abnormal protein accumulation, is then able to participate in the neurodegenerative process, by raising the production of a series of proinflammatory mediators which can be toxic to neurons [10]. Although several observations have confirmed a direct link between the neuroinflammatory reaction and disease pathogenesis in other tauopathies such as $\mathrm{AD}$ [11], the occurrence of inflammation in the brain of patients affected by FTDP-17T and its contribution to disease progression remain unknown. To address this issue, we studied microglia activation, IL- $1 \beta$ production and COX- 2 expression in the brain of a patient affected by familial FTDP-17T with a FTD phenotype caused by the P301S mutation in the tau gene and of a patient affected by a FTDP-17T with a different phenotype, multiple system tauopathy with presenile dementia (MSTD) linked to the +3 mutation in the intron following the exon 10 of the tau gene $[12,13]$.

\section{Methods}

\section{P301S Patient}

At the age of 29 years, this patient was affected by depressive mood, memory loss and difficulty in concentrating. Two years later grasp reflex, brisk tendon reflexes, slight rigidity, moderate defects of spoken expression, severe memory loss and inappropriate behavior were diagnosed. Subsequently, the patient presented progressive disorientation, inability to communicate as well as occasional visual and auditory hallucinations and persecutory delusions. Death occurred at 36 years of age.

\section{MSTD Patient}

This patient presented at the age of 52 years with disinhibition, social conduct disorder, dysexecutive symptoms and memory impairment. Progressive reduction of speech output was evident as well as personality changes and word-finding difficulties. Death occurred at the age of 58 years.

\section{Antibodies}

A monoclonal antibody (1:50, Dako Cytomation, Glosdrup, Denmark) directed against cluster of differentiation 68 (CD68) receptor was used to recognize microglia/macrophages. Activated microglia/macrophages were detected by a monoclonal antibody directed against the major histocompatibility complex class II receptors encoded by the human leukocyte antigen DP-DQ-DR (HLA-DP-DQ-DR; 1:50; Dako Cytomation). Two polyclonal antisera (1:200; Santa Cruz Biotechnology, Santa Cruz, Calif., USA) were used to detect IL-1 $\beta$ and COX-2. Monoclonal antibodies AT- 8 (1:750; Innogenetics, Ghent, Belgium) [14] and AT-100 (1:750; Innogenetics) [15] and polyclonal antiserum AP-422 [16] were used to detect tau phosphorylated at S202, T205 and T212, S214 and S422, respectively.

\section{Immunohistochemistry}

Paraffin-embedded cortical and hippocampal sections from the brain of the P301S and MSTD +3 patients were prepared as previously described $[4,12]$. For immunohistochemistry, paraffin-embedded sections were rehydrated, and antigen unmasking was performed boiling twice the sections in $10 \mathrm{mM}$ citrate buffer, $\mathrm{pH}$ 6.0, for $1 \mathrm{~s}$ with a 5 -min interval in the microwave. For singlelabeling immunohistochemistry, sections were rinsed in phosphate-buffered saline (PBS) $0.1 \mathrm{M}, \mathrm{pH} 7.4$, and then incubated at room temperature for $20 \mathrm{~min}$ with a solution of $0.3 \%$ Triton X-100, $20 \%$ methanol and $1.5 \% \mathrm{H}_{2} \mathrm{O}_{2}$ in PBS. This step was followed by a further 30-min incubation with blocking solution containing $0.3 \%$ Triton $\mathrm{X}-100,2 \mathrm{~g} / \mathrm{l}$ bovine serum albumin, and 3\%, normal 


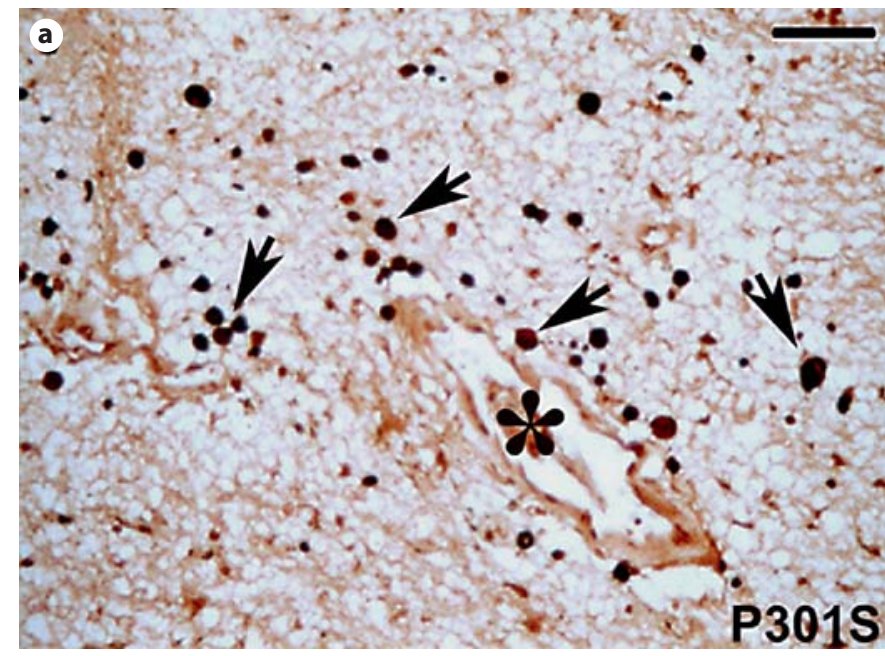

Fig. 1. CD68 (black staining) and AP-422 (red staining; colors in the online version only) double labeling. a CD68-positive roundshaped cells (arrows) in the hippocampal white matter of the patient with the P301S mutation. Note the abundance of these cells in the surroundings of the blood vessel (asterisk) indicative of macrophage infiltration. b CD68-immunoreactive cells (arrows) cluster around AP-422-positive neurons (red-labeled cells) in the hippocampal gray matter of the $\mathrm{P} 301 \mathrm{~S}$ patient. c High magnification of the square in $\mathbf{b}$ showing the round-shaped morphology of CD68-positive cells (arrows) in the surroundings of an AP-422positive neuron. d CD68 (black staining) and AP-422 (red staining) double labeling. In the brain of the patient with the +3 mutation, CD68-antibody-labeled cells with swollen cell bodies and thick shortened but still ramified processes in the parenchyma and in the surroundings of AP-422-positive neurons (indicated by the arrowheads). a, b, d Scale bar $=100 \mu \mathrm{m}$; c scale bar $=40$ $\mu \mathrm{m}$.

goat serum for the polyclonal antibodies or normal horse serum for the monoclonal antibodies in PBS. Sections were then incubated overnight at $4^{\circ} \mathrm{C}$ with the primary antibody diluted in blocking solution. On the second day, they underwent an incubation for $1 \mathrm{~h}$ at room temperature with the appropriate biotinylated secondary antibody (Vectastain; Vector Laboratories, Burlingame, Calif., USA) diluted 1:1,000 in blocking solution. The immunostaining was visualized with an avidin-biotin system (Vectastain; Vector Laboratories) and 3',3'-diaminobenzidine or SG substrate as the chromogen (DAB kit, SG kit; Vector Laboratories). Sections were then mounted on glass slides, examined using a light microscope (Leica Microsystems, Milton Keynes, UK) and photographed using a digital camera (Leica Microsystems). For double labeling, after diaminobenzidine staining, sections underwent another cycle of staining that was revealed with the Vector Nova Red kit (Vector Laboratories).

For colocalization experiments, after rehydration and antigen unmasking, sections were incubated for $30 \mathrm{~min}$ with blocking solution containing $0.25 \%$ Triton X-100, 5\% normal goat serum and $2 \mathrm{~g} / \mathrm{l}$ bovine serum albumin in $0.1 \mathrm{M}$ PBS, $\mathrm{pH}$ 7.4, and then overnight at $4^{\circ} \mathrm{C}$ with the primary antibody. On the second day, sec-
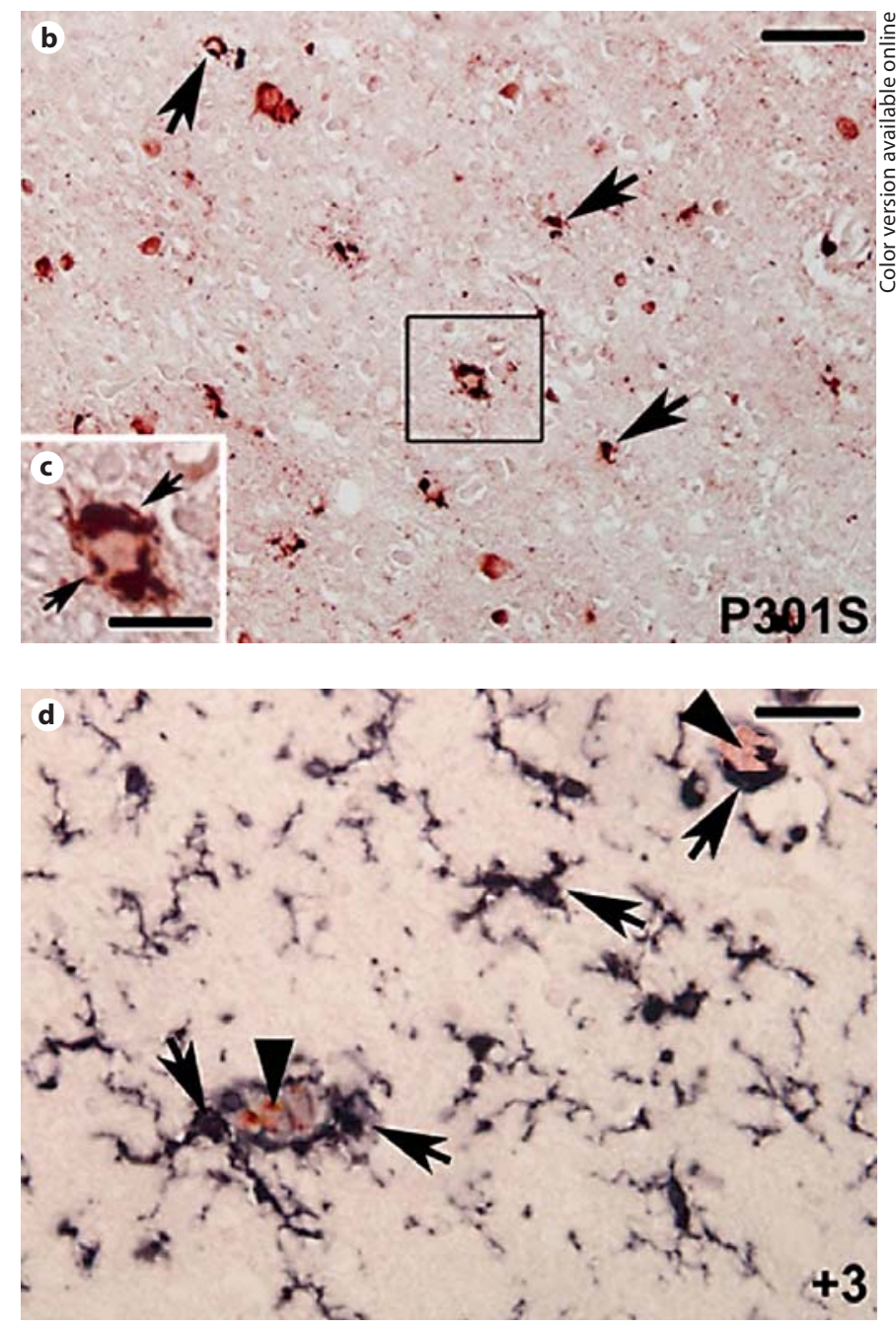

tions were incubated for $1 \mathrm{~h}$ in the dark with the appropriate fluorescent secondary antibody (FITC green or Cy5 red Alexa, Molecular Probes, Leiden, the Netherlands) diluted 1:200 in blocking solution. Sections were then incubated with the second primary antibody overnight at $4^{\circ} \mathrm{C}$. On the third day, slices were incubated for $1 \mathrm{~h}$ at room temperature with the second fluorescent antibody diluted 1:200 in blocking solution, then mounted on slides using Vectashield mounting medium (Vector Laboratories) and examined by fluorescence microscopy.

\section{Results}

\section{Microglia/Macrophages and Tau Double Labeling}

In the cortex and hippocampus of the patient bearing the P301S mutation, CD68 antibody, recognizing both microglial cells and macrophages [17], labeled numerous cells with ameboid morphology which were reminiscent 


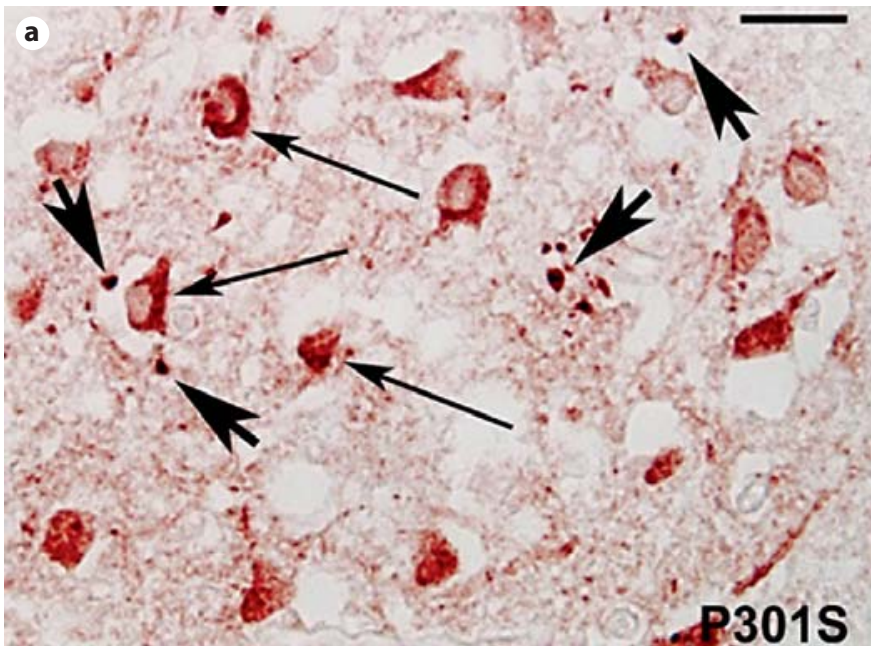

Fig. 2. HLA-DP-DQ-DR (black staining) and AP-422 (red staining; colors in the online version only) double labeling. a Cortex of the patient with the P301S mutation. Note the presence of numerous cells with ameboid morphology (large arrows) in the surroundings of AP-422-positive neurons (thin arrows, red cells).

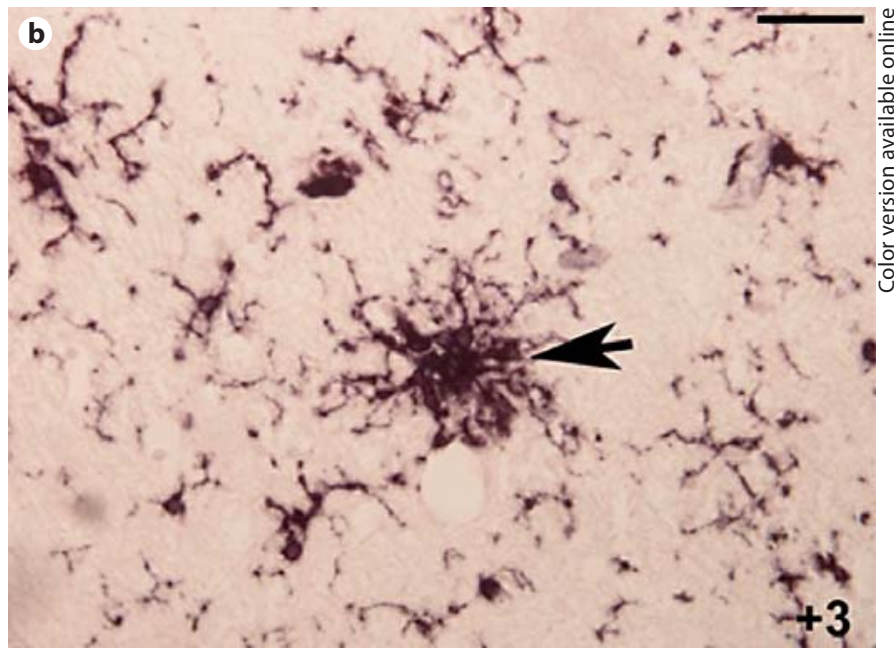

b Cortex of the patient affected by FTDP-17T with the +3 mutation. Note the presence of clusters of bushy activated HLA-DPDQ-DR-positive microglial cells (arrow). a Scale bar $=50 \mu \mathrm{m}$; b scale bar $=80 \mu \mathrm{m}$. of activated microglia (fig. 1a, arrows), in the parenchyma of the white matter, where they were found to be particularly concentrated around blood vessels (fig. la, asterisk), suggesting that a quota of these cells could be represented by perivascular microglia/infiltrating macrophages. In the gray matter of the cortex and hippocampus, numerous CD68-positive cells (fig. 1b, black staining) were present in the surroundings of AP-422-positive neurons (fig. $1 \mathrm{~b}$, red staining in the online version). Indeed, higher magnification of the area in the square in figure $1 \mathrm{~b}$ confirmed that CD68 immunoreactivity (fig. 1c, arrows) was localized around the phosphorylated-tau-positive neurons (fig. 1c, red staining in the online version).

In the brain of the patient affected by FTDP-17 with the +3 mutation (fig. 1d), activated CD68-positive cells displayed a branched microglial morphology with swollen cell bodies and thick and short but still ramified processes indicative of an early stage of activation. Some of these cells clustered around AP-422-positive neurons (fig. 1d, arrowheads).

Double labeling with AP-422 and HLA-DP-DQ-DR antibodies revealed that in the cortex (not shown) and hippocampus (fig. 2a) of the patient with the P301S mutation numerous HLA-DP-DQ-DR-positive cells (large arrows) with a round shape morphology reminiscent of activated microglia/macrophages were localized in the sur- roundings of AP-422-positive neurons (thin arrows). In the patient affected by MSTD (fig. 2b), activated microglial cells (arrow) with thick but long processes and swollen cell bodies clustered around AP-422-positive neurons.

Fig. 3. IL-1 $\beta$-positive cells in the brain of the patients with P301S $(\mathbf{a}-\mathbf{h})$ and +3 (i-k) mutations. a IL-1 $\beta$-staining in neuronal (large arrows) cells in the cortical gray matter. Please note the presence of numerous IL- $1 \beta$-positive dots (thin arrows). b IL-1 $\beta$-positive round-shaped dots in the white matter of the cortex (thin arrows). c, d Double-labeling immunofluorescence staining for IL-1 $\beta$ (green; colors in the online version only) and tau phosphorylated at S202 and T205 (antibody AT-8; red) in the hippocampus of the patient with the P301S mutation. e Merged image of the pictures in $\mathbf{c}$ and $\mathbf{d}$ showing the expression of IL- $1 \beta$ within the AT- 8 -positive neurons that is confirmed by the yellow color. $\mathbf{f}, \mathbf{g}$ Doublelabeling immunofluorescence staining for IL-1 $\beta$ (green) and tau phosphorylated at T212 and S214 (antibody AT-100; red) in the hippocampus of the patient with the P301S mutation. $\mathbf{h}$ Merged image of the pictures in $\mathbf{f}$ and $\mathbf{g}$ showing the expression of IL-1 $\beta$ within the AT-100-positive neurons that is confirmed by the yellow color. $\mathbf{i}$, j Double-labeling immunofluorescence staining for IL-1 $\beta$ (green) and AT-8-positive tau protein in the cortex of the patient with the +3 mutation. $\mathbf{k}$ Merged image of the pictures in $\mathbf{i}$ and $\mathbf{j}$ showing expression of IL- $1 \beta$ within some of the AT- 8 -positive neurons and degenerating neuritis as confirmed by the yellow color (arrows). $\mathbf{a}, \mathbf{i}-\mathbf{k}$ Scale bar $=150 \mu \mathrm{m}$; b scale bar $=210 \mu \mathrm{m}$; c-e scale bar $=100 \mu \mathrm{m}$; $\mathbf{f}-\mathbf{h}$ scale bar $=80 \mu \mathrm{m}$. 


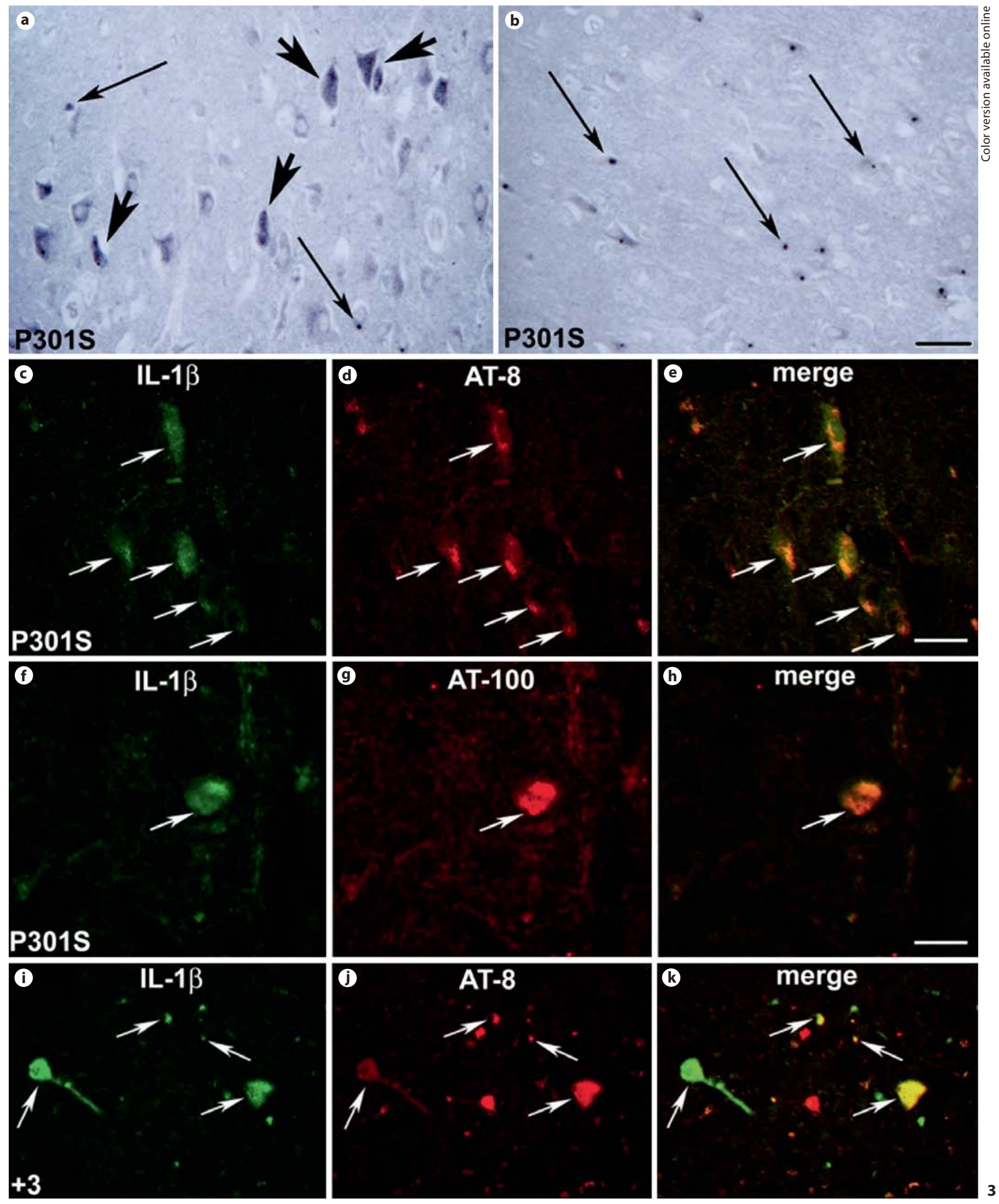



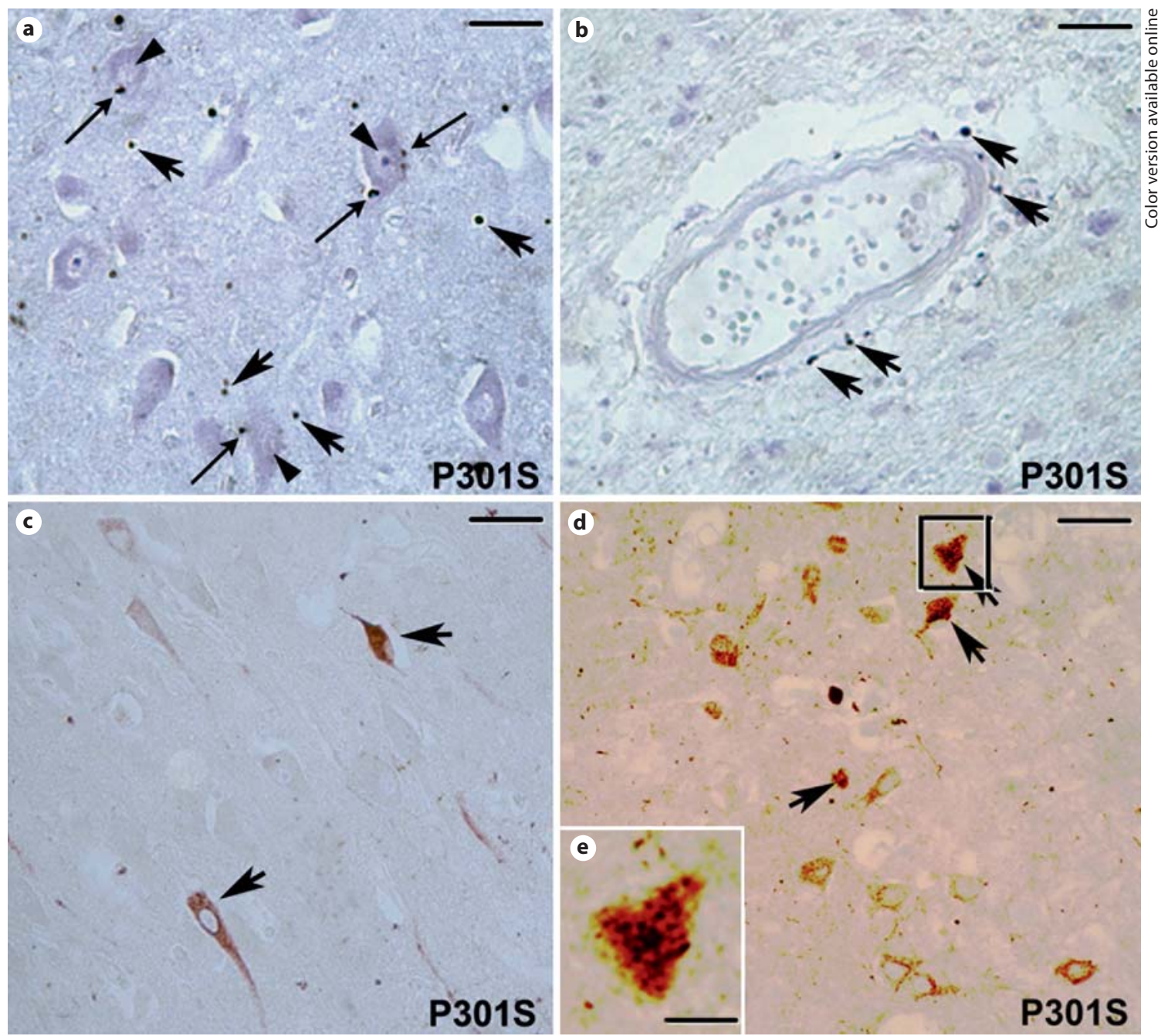

Fig. 4. COX-2 immunoreactivity in the brain of the patient with the P301S mutation. a COX-2-immunopositive round-shaped macrophage-like cells in the parenchyma (large arrows) and around (thin arrows) neurons (arrowheads) in the cortex. b Note the presence of COX-2-positive macrophage-like cells in the surroundings of blood vessels (arrows). c Some COX-2-positive neurons are present in the gray matter of the hippocampus (arrows). d Double labeling for COX-2 (black) and tau phosphorylated at

\section{IL-1 $\beta$ and COX-2 Immunoreactivity}

In the cortex and hippocampus of the P301S patient, numerous IL-1 $\beta$-positive cells were observed. In particular, we found that in the cortical (fig. 3a) and hippocampal (not shown) gray matter, IL-1 $\beta$-labeling was mostly localized in the cytoplasm of neurons. In the gray and white matter of the cortex (fig. 3a and b, respectively) and hippocampus (not shown), several IL-1 $\beta$-immunoreactive round-shaped dots were also visible. In the cortex
S202 and T205 (antibody AT-8; red in the online version only) in the hippocampus. Note the presence of COX-2 staining in phosphorylated-tau-positive neurons (arrow). e Higher magnification of the square in d. Please note the presence of the COX-2 dark labeling in the phosphorylated-tau-positive neuron. a Scale bar = $80 \mu \mathrm{m}$; b scale bar $=150 \mu \mathrm{m} ; \mathbf{c}$ scale bar $=165 \mu \mathrm{m} ; \mathbf{d}$ scale bar $=$ $170 \mu \mathrm{m}$. e scale bar $=35 \mu \mathrm{m}$.

(fig. $3 c, h$ ) and hippocampus (not shown), IL-1 $\beta$ labeling colocalized both with AT-8 (fig. 3d) and AT-100 (fig. 3g) immunoreactivities as shown by the merged images (fig. 3 e, h). In the patient with the +3 mutation (fig. $3 \mathrm{i}-\mathrm{k}$ ), only some of the AT-8-positive neurons showed IL-1 $\beta$ labeling (fig. 3i, arrows).

As for the IL-1 $\beta$ labeling, COX-2 immunoreactivity in the gray matter of the cortex (fig. 4a) and hippocampus (not shown) was localized in small round-shaped dots 
Table 1. Summary of the main immunohistochemical findings observed in the brain of the patients with the P301S or +3 mutations

\begin{tabular}{|c|c|c|c|c|}
\hline P301S & $\begin{array}{l}+++ \\
\text { Ameboid morphology, } \\
\text { around blood vessels, } \\
\text { around AP-422- } \\
\text { positive neurons, } \\
\text { in the parenchyma }\end{array}$ & $\begin{array}{l}+++ \\
\text { Ameboid morphology, around } \\
\text { AP-422-positive neurons }\end{array}$ & $\begin{array}{l}+ \\
\text { Observed in neuronal } \\
\text { cytoplasm, colocalized } \\
\text { with hyperphosphorylat- } \\
\text { ed tau; presence of some } \\
\text { immunoreactive dots }\end{array}$ & $\begin{array}{l}+ \\
\text { Observed in neuronal cyto- } \\
\text { plasm in some of the hyper- } \\
\text { phosphorylated-tau-positive } \\
\text { neurons; } \\
\text { some immunoreactive dots in } \\
\text { the parenchyma and around } \\
\text { blood vessels in the gray matter }\end{array}$ \\
\hline MSTD & $\begin{array}{l}\text { Branched morphology, } \\
\text { around AP-422- } \\
\text { positive neurons }\end{array}$ & $\begin{array}{l}++ \\
\text { Branched morphology, around } \\
\text { AP-422-positive neurons }\end{array}$ & $\begin{array}{l}+ \\
\text { Observed in neuronal } \\
\text { cytoplasm, partially } \\
\text { colocalized with the } \\
\text { hyperphosphorylated- } \\
\text { tau-positive neurons }\end{array}$ & Not detected \\
\hline
\end{tabular}

(indicated by the large arrows in fig. 4a). In these areas, COX-2-positive dots were located in the parenchyma of the gray matter (fig. 4a, large arrows) and around (fig. 4a, thin arrows) neuronal cell bodies (fig. $4 \mathrm{a}$, arrowheads). Furthermore, we observed that some COX-2-immunopositive dots were also localized in the surroundings of blood vessels (fig. 4b, arrows) as the CD68-immunopositive infiltrating cells. In the gray matter of the cortex (not shown) and hippocampus (fig. 4c), some COX-2positive neurons were also present. Double-labeling immunohistochemistry with COX-2 (black) and AT-8 (red in the online version) antibodies revealed that some of the hyperphosphorylated-tau-positive neurons were COX-2immunoreactive (indicated by the arrows in fig. $4 \mathrm{~d}$ ). Indeed, COX-2 labeling was localized within the cytoplasm of phosphorylated-tau-positive neurons (fig. 4e).

In the patient with the +3 mutation, no COX- 2 staining was visible (not shown).

\section{Discussion}

The results presented in this paper indicate that in the brain of patients affected by FTDP-17T bearing the P301S and +3 mutation, brain inflammation is differentially activated. The main differences between the neuroinflammatory changes observed in the patients bearing the P301S and +3 mutation have been summarized in table 1 .

In the brain of the P301S patient, CD68 and HLA-DR immunoreactivities were present in cells showing an ameboid phenotype with swollen cell bodies, reminiscent both of activated microglia and/or infiltrating macro- phages. These findings recall the microgliosis observed in the brain of the P301S transgenic mice [7] where we showed that a strong CD11b-positive microglia activation, with a small portion of cells expressing major histocompatibility complex class II antigens, is present in areas rich in phospho-tau-positive neurons. Indeed, in the brain of the P301S patient, these cells were particularly concentrated in the surroundings of phosphorylated-taupositive neurons in the cortex and hippocampus and other areas where phospho-tau-positive deposits were abundant, such as the subcortical white matter [4]. Furthermore, in agreement with the previous observations by Bugiani et al. [4], showing the presence of PAS-positive macrophages in demyelinated areas in the brain of the P301S patient, the presence of numerous CD-68-positive cells around blood vessels may indicate that the reactive microgliosis is likely accompanied by a remarkable macrophage infiltration. Indeed, although it is impossible to discriminate activated microglial cells from infiltrating macrophages on the basis of their morphological characteristics and biochemical markers, it is feasible that part of the perivascular and parenchymal ameboid cells could be infiltrating macrophages.

However, these findings may also indicate that activated microglia has evolved into a macrophagic state, a condition that occurs during chronic neuroinflammation, when neurons continue to send out activating signals [18]. This might have been the case of the P301S patient, as in his brain numerous phospho-tau-positive neurons were also positive for IL-1 $\beta$ and COX-2. These changes may have preceded another process, microglia degeneration, which induces a pathway of slow neuronal/ 
glial degeneration as a consequence of the loss of microglial support to neuronal cells [18]. Thus, the broad atrophy of the brain of the P301S patient might have been the result of the severe neuronal/glial cell loss which has occurred in response to the pathological hyperphosphorylated tau deposition.

Furthermore, we observed the presence of IL-1 $\beta$-positive round-shaped dots reminiscent of the activated ameboid microglial cells in the parenchyma of the gray matter and around neuronal cell bodies in the white matter. Interleukin- $1 \beta$ levels are known to be increased in the brain of $\mathrm{AD}$ patients [11]. Its production can be induced by noxious stimuli such as hypoxia, ischemia, traumatic insults and abnormal protein accumulation in microglia, astrocytes and neurons [19]. Functionally, IL-1 $\beta$ acts as a chemotactic factor, which has also been demonstrated to induce COX-2 in nerve cells [20,21], but recent findings indicate that IL-1 $\beta$ can also promote the expression and phosphorylation of tau protein in rats [22]. Together with our previous data on P301S transgenic mice [7], the present observations confirm that IL- $1 \beta$ expression can be induced in phospho-tau-positive neurons. Its induction might have driven multiple events such as microglia/ macrophage activation, tau protein phosphorylation and COX-2 expression. On the other hand, neuronal COX-2 induction could also have been involved in the onset of tau pathological alterations. Indeed, COX-2 induction results in the production of prostaglandins that may in turn activate several intracellular kinases such as the p38 mitogen-activated protein kinase which is known to phosphorylate tau on specific sites [23]. On this line, several studies indicate that COX-2 is induced in neuronal cells in the brain of patients affected by other tau-related diseases such as $\mathrm{AD}[24,25]$. Indeed, it has been described that in the AD brain COX-2 and cell cycle changes occur in the temporal cortex during early Braak stages prior to the maximal activation of astrocytes and microglia [26]. Thus, it may be feasible that COX-2 production by neuronal cells in the brain of the patient with the P301S mutation may reflect the activation of molecular mechanisms induced in response to intraneuronal accumulation of hyperphosphorylated tau, which may be involved in the onset of neuronal dysfunctions, rather than in the neuroinflammatory process. However, in the patient with the P301S mutation, COX-2 was expressed in neurons and in numerous round-shaped dots, in the parenchyma of the white matter and in the surroundings of several neurons in the gray matter. Remarkably, previous studies have shown that IL- $1 \beta$ does not stimulate COX-2 induction in microglial cells [27] except for perivascular microglia and infiltrating macrophages where COX-2 can be induced following IL-1 $\beta$ injection into the brain [28]. Thus, the COX-2-immunopositive dots could be either perivascular microglia or infiltrating macrophages which could have been stimulated by IL-1 $\beta$ production by neuronal cells.

As for the brain of the patient affected by MSTD bearing the +3 mutation, we also found evidence of microglia activation around phospho-tau-positive neurons, part of which were IL- $1 \beta$ positive. Nonetheless, it is important to outline that in the brain of this patient the CD68- and HLA-DP-DQ-DR-positive cells displayed an earlier phenotype of activation from a morphological examination and we did not detect COX-2 immunoreactivity. These findings may reflect important differences between the neuroinflammatory process observed in these patients. Indeed, our results indicate that in the patient with the P301S mutation, where there was an extensive neuronal tau pathology, the inflammatory reaction, involving neuronal, microglial and macrophage cells, was severely activated. In the brain of the patient bearing the +3 mutation, we also found evidence of an ongoing inflammatory process, as we observed an earlier stage of microglia activation and neuronal IL-1 $\beta$ production in hyperphosphorylated-tau-positive neurons, in the absence of ameboid cells and COX-2 induction. Whether the difference between the two cases is related to the fact that in the P301S case tau is mutated, while in the +3 case there is only an increase of the normal $4 \mathrm{R}$ tau, is not known.

Taken together our observations confirm that pathological tau alterations within neuronal cells are able to induce important neuroinflammatory changes in the brain. Activation of the brain inflammatory reaction in tauopathies may then differentially contribute to neuronal degeneration. For this reason, anti-inflammatory and immune-response-suppressing drugs may be taken into account as useful treatments for delaying the progression of neurodegenerative tauopathies such as FTDP-17T.

\section{Acknowledgements}

We are grateful to Prof. Fiorella Casamenti and Prof. Giancarlo Pepeu for insightful discussion. We thank Prof. Pier-Franco Spano and Dr. Ginetta Collo for reading the manuscript. We thank Dr. Ilaria Luccarini and Dr. Alessandro Fanzani for technical assistance. A. Bellucci was supported by a Studentship from the Italian Society of Pharmacology. This work was supported by the Medical Research Council, UK (to M.G.S.) and by the National Institute of Health, NIH AG010133 (to B.G.). 


\section{References}

$>1$ Wszolek ZK, Tsuboi Y, Farrer M, Uitti RJ, 11 Akiyama H, Barger S, Barnum S, Bradt B, Hutton ML: Hereditary tauopathies and parkinsonism. Adv Neurol 2003;91:153-163.

2 Baba Y, Baker MC, Le Ber I, Brice A, Maeck L, Kohlhase J, Yasuda M, Stoppe G, Bugiani O, Sperfeld AD, Tsuboi Y, Uitti RJ, Farrer MJ, Ghetti B, Hutton ML, Wszolek ZK: Clinical and genetic features of families with frontotemporal dementia and parkinsonism linked to chromosome 17 with a P301S tau mutation. J Neural Transm 2007;114:947-950.

-3 Gasparini L, Terni B, Spillantini MG: Frontotemporal dementia with tau pathology. Neurodegener Dis 2007;4:236-253.

-4 Bugiani O, Murrell JR, Giaccone G, Hasegawa M, Ghigo G, Tabaton M, Morbin M, Primavera A, Carella F, Solaro C, Grisoli M, Savoiardo M, Spillantini MG, Tagliavini F, Goedert M, Ghetti B: Frontotemporal dementia and corticobasal degeneration in a family with a P301S mutation in tau. J Neuropathol Exp Neurol 1999;58:667-677.

5 Bugiani O: FTDP-17: phenotypical heterogeneity within P301S. Ann Neurol 2000;48 126.

6 Allen B, Ingram E, Takao M, Smith MJ, Jakes R, Virdee K, Yoshida H, Holzer M, Craxton M, Emson PC, Atzori C, Migheli A, Crowther RA, Ghetti B, Spillantini MG, Goedert M: Abundant tau filaments and nonapoptotic neurodegeneration in transgenic mice expressing human P301S tau protein. J Neurosci 2002;22:9340-9351.

7 Bellucci A, Westwood AJ, Ingram E, Casamenti F, Goedert M, Spillantini MG: Induction of inflammatory mediators and microglial activation in mice transgenic for mutant human P301S tau protein. Am J Pathol 2004; 165:1643-1652.

-8 Yoshiyama Y, Higuchi M, Zhang B, Huang SM, Iwata N, Saido TC, Maeda J, Suhara T, Trojanowski JQ, Lee VM: Synapse loss and microglial activation precede tangles in a P301S tauopathy mouse model. Neuron 2007;53:337-351.

$>9$ Yoshiyama Y, Kojima A, Ishikawa C, Arai K: Anti-inflammatory action of donepezil ameliorates tau pathology, synaptic loss, and neurodegeneration in a tauopathy mouse model. J Alzheimers Dis 2010;22:295-306.

10 Wyss-Coray T, Mucke L: Inflammation in neurodegenerative disease - a double-edged sword. Neuron 2002;35:419-432. Bauer J, Cole GM, Cooper NR, Eikelenboom $\mathrm{P}$, Emmerling $\mathrm{M}$, Fiebich $\mathrm{BL}$, Finch $\mathrm{CE}$, Frautschy S, Griffin WS, Hampel H, Hull M, Landreth G, Lue L, Mrak R, Mackenzie IR, McGeer PL, O’Banion MK, Pachter J, Pasinetti G, Plata-Salaman C, Rogers J, Rydel R, Shen Y, Streit W, Strohmeyer R, Tooyoma I, van Muiswinkel FL, Veerhuis R, Walker D, Webster S, Wegrzyniak B, Wenk G, WyssCoray T: Inflammation and Alzheimer's disease. Neurobiol Aging 2000;21:383-421.

12 Spina S, Farlow MR, Unverzagt FW, Kareken DA, Murrell JR, Fraser G, Epperson F, Crowther RA, Spillantini MG, Goedert M, Ghetti B: The tauopathy associated with mutation +3 in intron 10 of tau: characterization of the MSTD family. Brain 2008;131:72-89.

-13 Spillantini MG, Murrell JR, Goedert M, Farlow MR, Klug A, Ghetti B: Mutation in the tau gene in familial multiple system tauopathy with presenile dementia. Proc Natl Acad Sci USA 1998;95:7737-7741.

14 Goedert M, Jakes R, Vanmechelen E: Monoclonal antibody AT8 recognises tau protein phosphorylated at both serine 202 and threonine 205. Neurosci Lett 1995;189:167-169.

15 Zheng-Fischhofer Q, Biernat J, Mandelkow EM, Illenberger S, Godemann R, Mandelkow E: Sequential phosphorylation of tau by glycogen synthase kinase-3beta and protein kinase A at Thr212 and Ser214 generates the Alzheimer-specific epitope of antibody AT100 and requires a paired-helical-filament-like conformation. Eur J Biochem 1998;252:542-552.

16 Hasegawa M, Jakes R, Crowther RA, Lee VM, Ihara Y, Goedert M: Characterization of mAb AP422, a novel phosphorylation-dependent monoclonal antibody against tau protein. FEBS Lett 1996;384:25-30.

17 Guillemin GJ, Brew BJ: Microglia, macrophages, perivascular macrophages, and pericytes: a review of function and identification. J Leukoc Biol 2004;75:388-397.

18 Graeber MB, Streit WJ: Microglia: biology and pathology. Acta Neuropathol 2010;119: 89-105.

19 Rothwell NJ, Luheshi GN: Interleukin 1 in the brain: biology, pathology and therapeutic target. Trends Neurosci 2000;23:618-625.
20 Serou MJ, De Coster MA, Bazan NG: Interleukin-1 beta activates expression of cyclooxygenase- 2 and inducible nitric oxide synthase in primary hippocampal neuronal culture: platelet-activating factor as a preferential mediator of cyclooxygenase-2 expression. J Neurosci Res 1999;58:593-598.

21 Hoozemans JJ, Veerhuis R, Janssen I, Rozemuller AJ, Eikelenboom P: Interleukin-1beta induced cyclooxygenase 2 expression and prostaglandin $\mathrm{E}_{2}$ secretion by human neuroblastoma cells: implications for Alzheimer's disease. Exp Gerontol 2001;36:559-570.

22 Sheng JG, Zhu SG, Jones RA, Griffin WS, Mrak RE: Interleukin-1 promotes expression and phosphorylation of neurofilament and tau proteins in vivo. Exp Neurol 2000;163: 388-391.

-23 Reynolds CH, Betts JC, Blackstock WP, Nebreda AR, Anderton BH: Phosphorylation sites on tau identified by nanoelectrospray mass spectrometry: differences in vitro between the mitogen-activated protein kinases ERK2, c-Jun N-terminal kinase and p38, and glycogen synthase kinase-3beta. J Neurochem 2000;74:1587-1595.

24 Pasinetti GM, Aisen PS: Cyclooxygenase-2 expression is increased in frontal cortex of Alzheimer's disease brain. Neuroscience 1998;87:319-324.

25 Hoozemans JJ, Rozemuller AJ, Janssen I, de Groot CJ, Veerhuis R, Eikelenboom P: Cyclooxygenase expression in microglia and neurons in Alzheimer's disease and control brain. Acta Neuropathol 2001;101:2-8.

26 Hoozemans JJ, van Haastert ES, Veerhuis R, Arendt T, Scheper W, Eikelenboom P, Rozemuller AJ: Maximal COX-2 and ppRb expression in neurons occurs during early Braak stages prior to the maximal activation of astrocytes and microglia in Alzheimer's disease. J Neuroinflammation 2005;2:27.

27 Hoozemans JJ, Veerhuis R, Janssen I, van Elk EJ, Rozemuller AJ, Eikelenboom P: The role of cyclo-oxygenase 1 and 2 activity in prostaglandin $\mathrm{E}_{2}$ secretion by cultured human adult microglia: implications for Alzheimer's disease. Brain Res 2002;951:218-226.

28 Minghetti L, Walsh DT, Levi G, Perry VH: In vivo expression of cyclooxygenase-2 in rat brain following intraparenchymal injection of bacterial endotoxin and inflammatory cytokines. J Neuropathol Exp Neurol 1999;58: 1184-1191. 